\title{
ГАЛЛОЦИАНИН КАК ФЛУОРОГЕН ДЛЯ ВЫЯВЛЕНИЯ NАDРН-ЗАВИСИМОЙ ПРОДУКЦИИ СУПЕРОКСИДНОГО АНИОН-РАДИКАЛА КЛЕТКАМИ КРОВИ
}

\author{
(С) 2021 г. О. М. Панасенко*, \#, В. Е. Реут**, И. В. Бородина*, Д. С. Матюшкина*, \\ В. А. Иванов*, Д. В. Григорьева ${ }^{* *}$, И. В. Горудко**, А. В. Соколов*, ***, С. Н. Черенкевич** \\ *ФГБУ “Федеральный научно-клинический центр физико-химической медицины” ФМБА России, \\ Россия, 119435 Москва, ул. Малая Пироговская, 1 а \\ ** Белорусский государственный университет, Беларусь, 220030 Минск, просп. Независимости, 4 \\ *** Институт экспериментальной медицины, Россия, 197376 Санкт-Петербург, ул. Академика Павлова, 12 \\ Поступила в редакцию 09.04.2020 г. \\ После доработки 18.04.2020 г. \\ Принята к публикации 21.04.2020 г.
}

\begin{abstract}
Методами спектрофотометрии, масс-спектрометрии и спектрофлуориметрии исследовано взаимодействие красителя оксазинового ряда галлоцианина с активными формами кислорода $\left({ }^{\circ} \mathrm{O}_{2}^{-}, \mathrm{H}_{2} \mathrm{O}_{2}\right)$

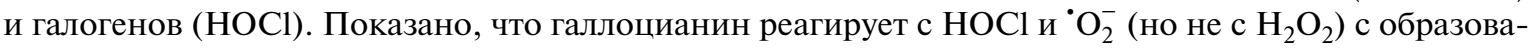
нием флуоресцирующих продуктов. С использованием ингибиторного анализа установлено, что как в системе ксантин/ксантиноксидаза, так и в присутствии активированных нейтрофилов крови человека основной вклад в превращение галлоцианина во флуорофор вносит его реакция с ${ }^{\circ} \mathrm{O}_{2}^{-}$. Полученные результаты позволяют заключить, что галлоцианин может выполнять роль флуорогенного хемосенсора и использоваться для оценки активации нейтрофилов, NADPH-зависимой продукции супероксидного анион-радикала нейтрофилами и другими клетками крови, а также для тестирования антиоксидантных препаратов, разрабатываемых с целью коррекции заболеваний, ассоциированных с окислительным стрессом.
\end{abstract}

Ключевые слова: галлоцианин, активные формы кислорода, активные формы галогенов, окислительный стресс, супероксидный анион-радикал, хлорноватистая кислота, флуоресценция

DOI: $10.31857 / \mathrm{S} 0132342321010176$

\section{ВВЕДЕНИЕ}

Нейтрофилы представляют собой самый многочисленный подвид гранулоцитарных лейкоцитов (до 70\%) крови человека, играющий ключевую роль в реализации клеточного звена врожденного иммунитета во многом благодаря продукции активных форм кислорода (АФК) и галогенов (АФГ). Эти соединения не только играют роль медиаторов важных внутриклеточных и межклеточных редокс-чувствительных сигнальных путей, таких как ионная проницаемость, апоптоз, нетоз и рецепторные взаимодействия, но и, будучи высокореакционными, уничтожают патогены (бак-

Сокращения: 4-АВАН - гидразид 4-аминобензойной кислоты; CP - церулоплазмин; fMLP - N-формил-метиллейцил-фенилаланин; МРО - миелопероксидаза; РМА форбол-12-миристат-13-ацетат; SOD - супероксиддисмутаза; АФГ - активные формы галогенов; АФК - активные формы кислорода; ФСБ - фосфатно-солевой буфер.

\# Автор для связи: (тел.: +7 (499) 246-44-90; эл. почта: o-panas@mail.ru). терии, вирусы, грибы и др.), выполняя антимикробную функцию [1]. За продукцию АФК и АФГ в нейтрофилах отвечают главным образом ферменты: NADPH-оксидаза (КФ 1.6.3.1), супероксиддисмутаза (SOD, КФ 1.15.1.1) и миелопероксидаза (MPO, КФ 1.11.2.2). Активация нейтрофилов в ответ на провоспалительный стимул сопровождается сборкой NADPH-оксидазного комплекса, который катализирует реакцию восстановления молекулярного кислорода $\left(\mathrm{O}_{2}\right)$ до супероксидного анион-радикала $\left({ }^{\circ} \mathrm{O}_{2}^{-}\right)$[2]:

$$
\mathrm{NADPH}+2 \mathrm{O}_{2} \rightarrow \mathrm{NADP}^{+}+2^{\circ} \mathrm{O}_{2}^{-}+\mathrm{H}^{+} \text {. }
$$

В результате дисмутации ${ }^{\circ} \mathrm{O}_{2}^{-}$(спонтанной или катализируемой SOD) образуется пероксид водорода $\left(\mathrm{H}_{2} \mathrm{O}_{2}\right)$ :

$$
2^{\circ} \mathrm{O}_{2}^{-}+2 \mathrm{H}^{+} \rightarrow \mathrm{O}_{2}+\mathrm{H}_{2} \mathrm{O}_{2},
$$

являющийся субстратом фермента азурофильных гранул нейтрофилов - МРО [1, 3]. МРО в организ- 
ме человека катализирует главным образом окисление хлорида до хлорноватистой кислоты (HOCl):

$$
\mathrm{H}_{2} \mathrm{O}_{2}+\mathrm{Cl}^{-}+\mathrm{H}^{+} \rightarrow \mathrm{HOCl}+\mathrm{H}_{2} \mathrm{O} .
$$

АФК и особенно АФГ (включая $\mathrm{HOCl}$ ), образующиеся при активации нейтрофилов и обладающие повышенной реакционной способностью, реагируют со многими биологически важными молекулами (нуклеиновыми кислотами, белками, липидами, антиоксидантами и др.), повреждают клетки и ткани организма, вызывая окислительный/галогенирующий стресс, провоцирующий развитие воспалительных заболеваний: сердечно-сосудистых, нейродегенеративных, онкологических и др. [3-5]. Становится понятно, насколько важно контролировать и оценивать активность ферментов, ответственных за образование АФК и АФГ. Очевидно, что регистрация продукции клетками АФК/АФГ дает возможность разработки новых методов и подходов, направленных на профилактику, диагностику и мониторинг эффективности терапии заболеваний, ассоциированных с окислительным/галогенирующим стрессом. Среди методов, используемых для обнаружения АФК и АФГ (масс-спектрометрия в сочетании с различными вариантами хроматографии, иммуноферментный анализ, хемилюминесценция, спиновые ловушки и др.), флуоресцентный анализ отличается высокой чувствительностью и доступностью [6-8].

В последнее время предложено большое количество низкомолекулярных флуорогенных зондов, позволяющих в том числе в режиме реального времени регистрировать продукцию различных АФК и АФГ как внутри, так и вне клетки: 2', 7'-дихлордигидрофлуоресцеиндиацетат, дигидрородамин 123, 10-ацетил-3,7-дигидроксифеноксазин (Amplex $\mathrm{Red})$, аминофенилфлуоресцеин (2-[6-(4'-амино)фенокси-3H-ксантен-3-он-9-ил]бензойная кислота) и др. [6-11]. Однако указанные зонды не всегда являются достаточно чувствительными и специфичными при анализе тех или иных АФК/АФГ, зачастую их синтез весьма трудоемок, что значительно увеличивает стоимость, либо они попросту неудобны в анализе (плохая растворимость в воде, недостаточная стабильность и т.п.). Например, упомянутые 2',7'-дихлордигидрофлуоресцеиндиацетат, дигидрородамин 123 и аминофенилфлуоресцеин одинаково хорошо окисляются свободными радикалами, пероксинитритом и $\mathrm{HOCl}[6,9]$. Amplex Red, предназначенный для определения $\mathrm{H}_{2} \mathrm{O}_{2}$ в присутствии пероксидаз, легко окисляется под действием АФГ. Более того, такие восстановители, как NADH и глутатион, могут заметно искажать результат анализа $[10,11]$.

Ранее нами был предложен кинетический спектрофотометрический метод для измерения галогенирующей активности МРО, основанный на обесцвечивании под действием АФГ красителя оксазинового ряда - целестинового синего В [12]. Позднее мы показали, что этот краситель с успехом может быть использован для выявления $\mathrm{HOCl}$, продуцируемой активированными нейтрофилами, методами проточной цитометрии и конфокальной микроскопии [13].

В настоящей работе мы сосредоточили свое внимание на другом красителе оксазинового ряда галлоцианине (4-гидрокси-7-диметиламино-1карбоксифеноксазон-3 хлорид). Он - структурный аналог целестинового синего В, но отличается большей фотостабильностью, относительно хорошей растворимостью в фосфатно-солевом буфере и легко синтезируется с выходом, близким к количественному. Благодаря в том числе этим свойствам, галлоцианин уже более полувека используется при гистологическом анализе для окраски ядер [14] и количественного определения нуклеиновых кислот [15]. Нами было исследовано взаимодействие галлоцианина с основными АФК $\left({ }^{\circ} \mathrm{O}_{2}^{-}, \mathrm{H}_{2} \mathrm{O}_{2}\right)$ и АФГ $(\mathrm{HOCl})$ с целью использования красителя для выявления продукции этих соединений активированными нейтрофилами.

\section{РЕЗУЛЬТАТЫ И ОБСУЖДЕНИЕ}

Взаимодействие галлоцианина с ${ }^{\cdot} \mathrm{O}_{2}^{-}$. Известно, что диоксид калия $\left(\mathrm{KO}_{2}\right)$ в водной среде гидролизуется с образованием короткоживущего супероксидного анион-радикала:

$$
\mathrm{KO}_{2}+\mathrm{H}_{2} \mathrm{O} \rightarrow \mathrm{H}^{+}+\mathrm{KOH}+{ }^{\circ} \mathrm{O}_{2}^{-},
$$

который быстро дисмутирует до пероксида водорода по реакции (2). Суммарное уравнение реакции выглядит так:

$$
2 \mathrm{KO}_{2}+2 \mathrm{H}_{2} \mathrm{O} \rightarrow 2 \mathrm{KOH}+\mathrm{H}_{2} \mathrm{O}_{2}+\mathrm{O}_{2} .
$$

Для исследования взаимодействия галлоциа-

нина с ${ }^{\circ} \mathrm{O}_{2}^{-}$к раствору галлоцианина добавляли навеску сухого $\mathrm{KO}_{2}$, перемешивали и регистрировали спектры поглощения в видимой области (400-750 нм). Результаты измерения приведены на рис. 1. Видно, что раствор галлоцианина имеет максимум поглощения при 623 нм. По мере увеличения концентрации добавленного $\mathrm{KO}_{2}$ наблюдается снижение высоты этого пика, одновременно появляется пик поглощения с максимумом при 510 нм, увеличивается его интенсивность, при этом окраска раствора меняется с синей на бледно-фиолетовую. В совокупности это свидетельствует о расходовании галлоцианина и образовании как минимум одного продукта. В контрольных экспериментах мы показали, что добавление к галлоцианину (20 мкM) раствора $\mathrm{H}_{2} \mathrm{O}_{2}(10-1000$ мкM), образующегося по реакции (4), не приводит к изменению 


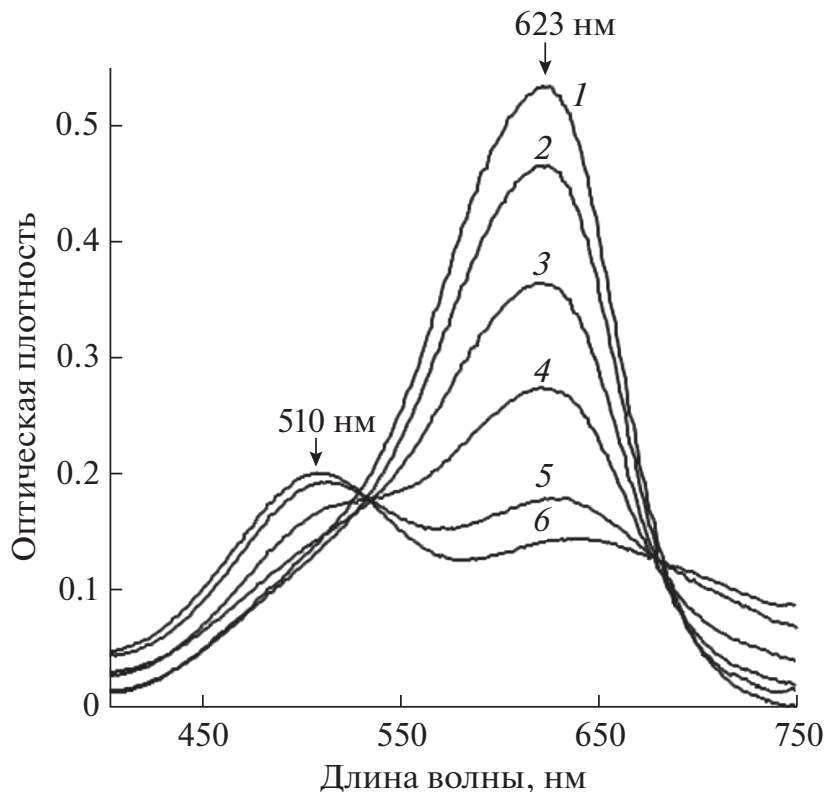

Рис. 1. Спектры поглощения галлоцианина до и после добавления к нему $\mathrm{KO}_{2}$. Среда измерения - ФСБ-2, pH 7.4 (см. “Эксперим. часть”). Концентрация галлоцианина - 20 мкМ. Концентрация $\mathrm{KO}_{2}(\mathrm{MM}): 1-0$; $2-0.22 ; 3-0.76 ; 4-0.98 ; 5-1.31 ; 6-1.64$.

спектра поглощения галлоцианина (данные не приведены). Это значит, что галлоцианин не вступает в реакцию с $\mathrm{H}_{2} \mathrm{O}_{2}$. В таком случае можно заключить, что изменение спектра поглощения галлоцианина при добавлении к нему $\mathrm{KO}_{2}$ обусловлено его реакцией с ${ }^{\circ} \mathrm{O}_{2}^{-}$, образующимся в качестве интермедиата при гидролизе $\mathrm{KO}_{2}$ по реакции (3).

Этот факт подтверждают изображенные на рис. 2 масс-спектры галлоцианина, зарегистрированные до и после добавления к нему $\mathrm{KO}_{2}$ в различных концентрациях. Масс-спектр галлоцианина (спектр 1 на рис. 2) представляет собой моноизотопное распределение, максимально интенсивный пик $(m / z, 301.1)$ соответствует массе катиона $\left[\mathrm{C}_{15} \mathrm{H}_{13} \mathrm{~N}_{2} \mathrm{O}_{5}\right]^{+}$, состоящего из основных изотопов $\left({ }^{12} \mathrm{C},{ }^{1} \mathrm{H},{ }^{14} \mathrm{~N},{ }^{16} \mathrm{O}\right)$. По мере роста концентрации $\mathrm{KO}_{2}$ сначала появляется (спектр 2 на рис. 2), увеличивается (спектры 3 и 4), а затем исчезает (спектр 5) сигнал с $m / z$ 339.1. Параллельно, начиная с концентрации $\mathrm{KO}_{2} 2.84$ мМ, появляется и увеличивается сигнал с $m / z$ 230.0. При концентрации $\mathrm{KO}_{2} 11.38$ мМ (спектр 5 на рис. 2) пик от исходного галлоцианина $(m / z$ 301.1) исчезает полностью и остается только сигнал с $m / z 230.0$. Такой результат можно объяснить, если предположить, что в реакции галлоцианина с $\mathrm{KO}_{2}$ сначала образуется продукт с $m / z$ 339.1, который в конце концов превращается в соединение с $m / z$ 230.0. Как минимум один из продуктов является флуо-

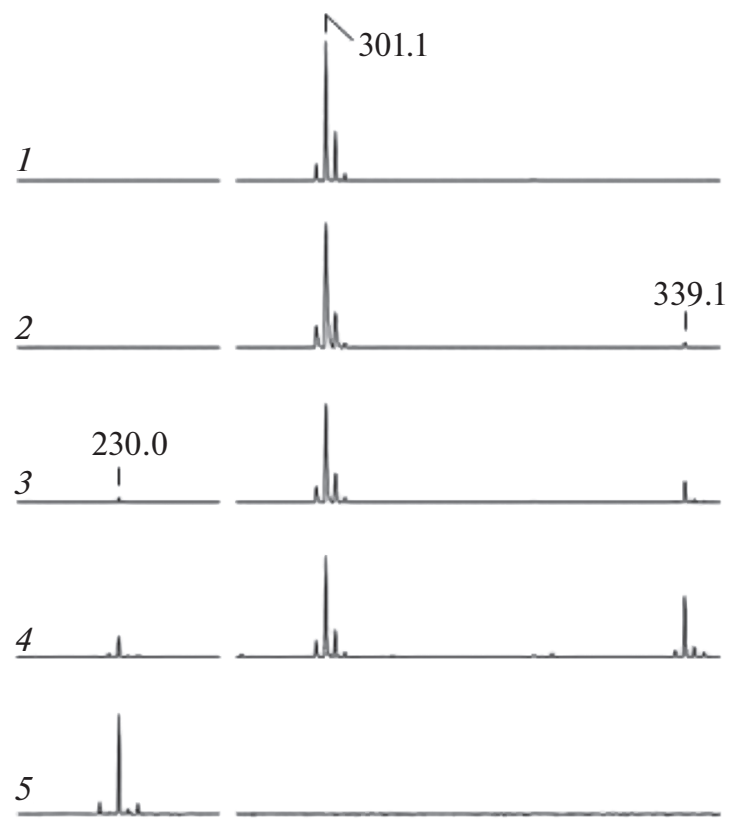

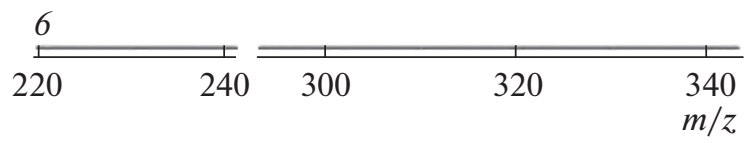

Pис. 2. Масс-спектры галлоцианина до и после добавления к нему $\mathrm{KO}_{2}$. Среда измерения - ФСБ-2, pН 7.4 (см. “Эксперим. часть”). Концентрация галлоцианина -80 мкМ. Концентрация $\mathrm{KO}_{2}(\mathrm{MM}): 1-0 ; 2-1.14$; $3-2.84 ; 4-5.69 ; 5-11.38 ; 6-$ масс-спектр матрицы (2,5-дигидроксибензойной кислоты) в отсутствие галлоцианина.

рофором, что подтверждают результаты, приведенные на рис. 3 , из которого видно, что добавление к раствору галлоцианина $\mathrm{KO}_{2}$ приводит к возникновению флуоресценции, которая усиливается по мере увеличения концентрации $\mathrm{KO}_{2}$ (максимумы в спектре возбуждения в области 260-370 нм, испускания - 480-500 нм, рис. 3).

Помимо $\mathrm{KO}_{2}$ для продукции ${ }^{\circ} \mathrm{O}_{2}^{-}$нами был использован фермент ксантиноксидаза, который в присутствии ксантина катализирует восстановление $\mathrm{O}_{2}$ до $\mathrm{O}_{2}^{-}$[16]. Результаты эксперимента приведены на рис. 4. Видно, что в присутствии ксантиноксидазы и ее субстрата ксантина наблюдается увеличение интенсивности флуоресценции при 490 нм (возбуждение при 360 нм) (кривая 1 на рис. 4), тогда как в отсутствие ксантина ферментативная реакция не идет, и прирост интенсивности флуоресценции отсутствует (кривая 2 на рис. 4). Этот результат свидетельствует о взаимодействии синтезирующегося в ферментативной реакции ${ }^{\circ} \mathrm{O}_{2}^{-}$с галлоцианином с образованием флуорофора. Из данных, представленных на рис. 5, 


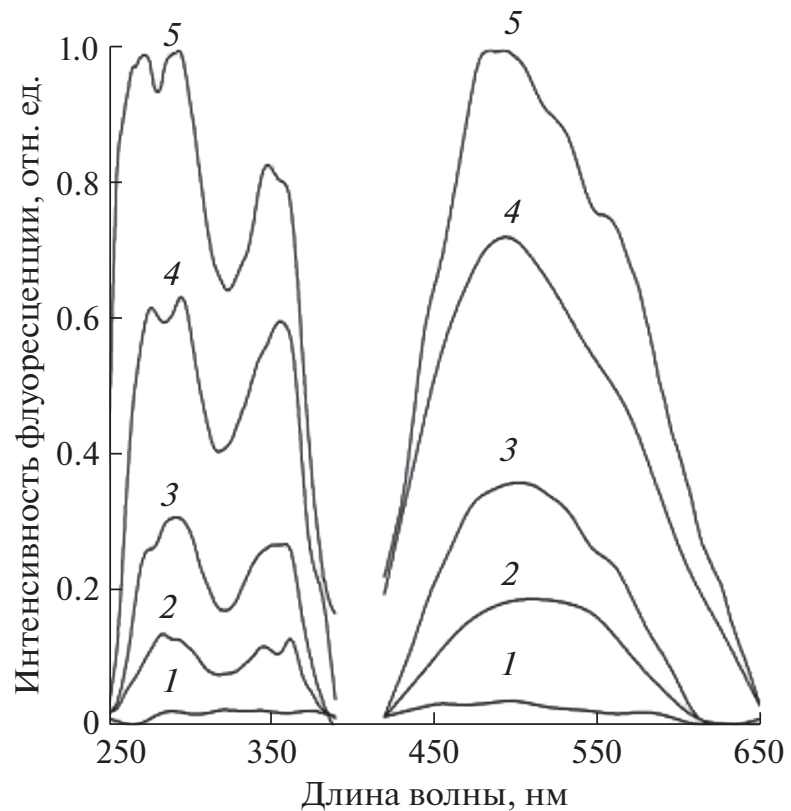

Рис. 3. Спектры возбуждения и испускания флуоресценции галлоцианина до и после добавления к нему $\mathrm{KO}_{2}$. Среда измерения - ФСБ-1, рН 7.4 (см. “Эксперим. часть”). Концентрация галлоцианина 5 мкМ. Концентрация $\mathrm{KO}_{2}$ (мМ): $1-0 ; 2-0.7 ; 3-1.6$; $4-2.7 ; 5-4.1$. Возбуждение - при 360 нм, испускание - при 490 нм.

видно, что интенсивность флуоресценции $\left(h_{20}\right)$ и химическая реакция галлоцианина $(v)$ в системе ксантин/ксантиноксидаза практически полностью подавляются в присутствии SOD. Этот факт свидетельствует о решающем вкладе ${ }^{\circ} \mathrm{O}_{2}^{-}$в химические превращения красителя.

Взаимодействие галлоцианина с НОСІ. На рис. 6 приведены спектры поглощения галлоцианина до и после добавления к нему $\mathrm{HOCl}$ в различных концентрациях. Видно, что раствор галлоцианина имеет максимум поглощения при 623 нм (спектр 1 на рис. 6a). Рассчитанный из этого спектра молярный коэффициент экстинкции составил $\varepsilon_{623}=28000 \mathrm{M}^{-1} \mathrm{~cm}^{-1}$, что хорошо согласуется с данными литературы [17, 18]. Добавление $\mathrm{HOCl}$ к красителю приводило к уменьшению оптической плотности раствора при длине волны 623 нм и появлению менее интенсивной полосы поглощения с максимумом при 475 нм (рис. $6 a$ ), что свидетельствует об образовании продукта реакции. Из вставки на рис. $6 a$ видно, что падение концентрации галлоцианина происходит пропорционально концентрации добавленной $\mathrm{HOCl}$ так, что коэффициент стехиометрии $\mathrm{HOCl}$ : галлоцианин равен 1.5. Однако, как видно из рис. 66 , дальнейшее увеличение концентрации $\mathrm{HOCl}$ приводит к снижению оптической плотности раствора при 475 нм и появлению полосы поглощения при

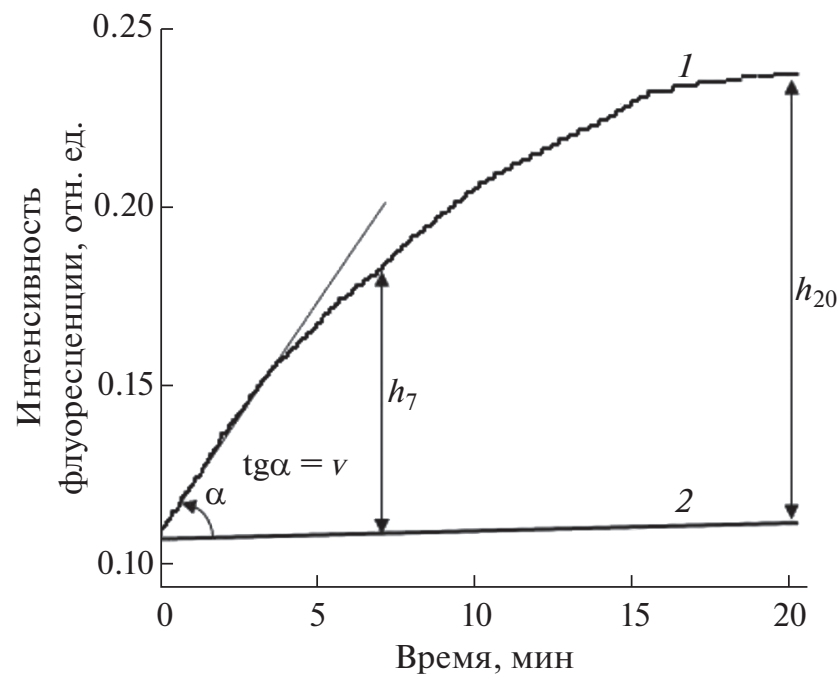

Рис. 4. Кинетика изменения интенсивности флуоресценции галлоцианина в системе ксантин/ксантиноксидаза (кривая 1). Концентрация галлоцианина -5 мкМ, ксантина - 1 мМ, ксантиноксидазы - 0.52 мкМ. Среда измерения - ФСБ-1, рН 7.4 (см. “Эксперим. часть”). Кривая 2 - контрольная кривая, полученная в отсутствие ксантина. Возбуждение - при 360 нм, испускание - при 490 нм. На рисунке обозначены определяемые параметры: интенсивность флуоресценции по сравнению с фоновым уровнем через $7\left(h_{7}\right)$ или $20\left(h_{20}\right)$ мин после запуска реакции и скорость химического превращения галлоцианина (v).

416 нм. В ходе реакции сине-фиолетовая окраска исходного раствора галлоцианина сначала меняется на оранжевую, а при дальнейшем увеличении концентрации $\mathrm{HOCl}$ раствор обесцвечивается. Такой результат говорит о том, что $\mathrm{HOCl}$ реагирует с галлоцианином с образованием как минимум двух продуктов, первый из которых, имеющий полосу поглощения при 475 нм, является промежуточным и при более высоких концентрациях $\mathrm{HOCl}$ претерпевает превращение в продукт, поглощающий при 416 нм.

Такой вывод подтверждают и приведенные на рис. 7 масс-спектры галлоцианина, зарегистрированные до и после добавления к нему $\mathrm{HOCl}$ в различных концентрациях. Видно, что по мере увеличения концентрации $\mathrm{HOCl}$ интенсивность сигнала, соответствующего массе катиона исходного галлоцианина $\left[\mathrm{C}_{15} \mathrm{H}_{13} \mathrm{~N}_{2} \mathrm{O}_{5}\right]^{+}(\mathrm{m} / \mathrm{z} 301.1)$, постепенно снижается. Параллельно появляются сигналы с $m / z, 328.3$ и 452.0, по всей вероятности, соответствующие двум продуктам реакции $\mathrm{HOCl}$ с галлоцианином. Как минимум один из этих продуктов является флуорофором. Об этом свидетельствуют представленные на рис. 8 спектры возбуждения и испускания флуоресценции раствора галлоцианина после добавления к нему $\mathrm{HOCl}$ в различных концентрациях. Видно, что по мере возрастания концентрации добавленной к галлоцианину $\mathrm{HOCl}$ наблюдается увеличение интенсивно- 


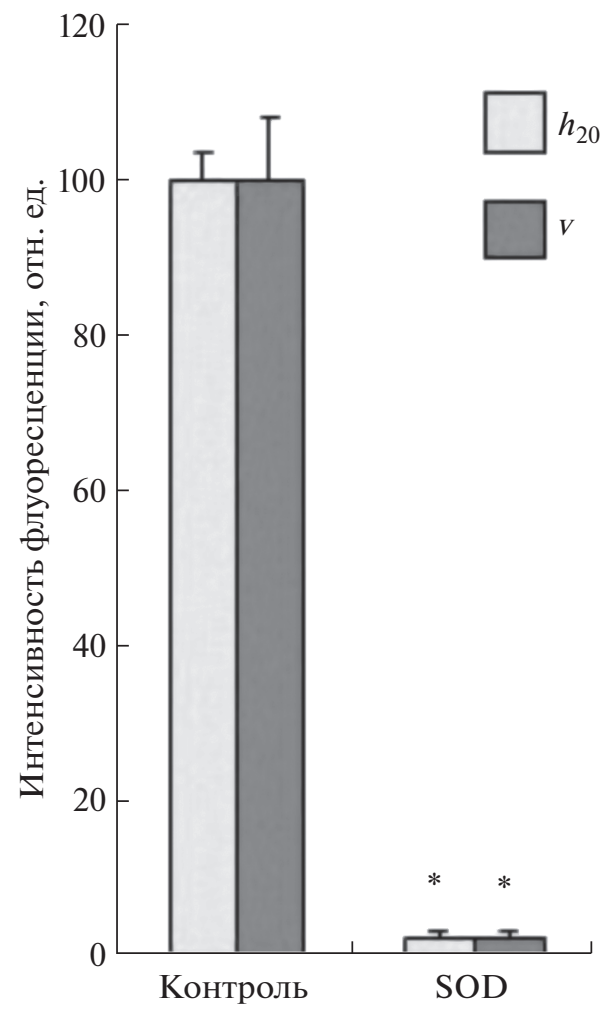

Рис. 5. Влияние SOD (1.6 мкM) на интенсивность $\left(h_{20}\right)$ и скорость нарастания флуоресценции $(v)$ в системе галлоцианин + ксантин/ксантиноксидаза. Концентрация галлоцианина - 5 мкM, ксантина - 1 мМ, ксантиноксидазы - 0.52 мкМ. Среда измерения ФСБ-1, рН 7.4 (см. “Эксперим. часть”). Возбуждение при 360 нм, испускание - при 490 нм. сти флуоресценции раствора красителя (максимумы в спектре возбуждения - 269, 292 и 360 нм, испускания - 490 нм, рис. 8), что обусловлено образованием продукта реакции.

Таким образом, оба исследованных нами реагента ( ${ }^{\circ} \mathrm{O}_{2}^{-}$и $\left.\mathrm{HOCl}\right)$ в бесклеточной среде реагируют с галлоцианином с образованием флуоресцирующих продуктов. Далее мы попытались выяснить, можно ли использовать галлоцианин в качестве флуорогенного хемосенсора для регистрации продукции АФК и/или АФГ нейтрофилами крови человека.

Продукция ' $\mathrm{O}_{2}^{-}$нейтрофилами. Известно, что среди всех клеток крови нейтрофилы являются основными носителями МРО и NADPH-оксидазы. Стимуляция нейтрофилов приводит, с одной стороны, к сборке и активации NADPH-оксидазного ферментного комплекса, что сопровождается усиленной продукцией ${ }^{\circ} \mathrm{O}_{2}^{-}$[2], а с другой $-\mathrm{K}$ дегрануляции клеток, секреции МРО из азурофильных гранул во внеклеточное пространство и, как следствие - к синтезу $\mathrm{HOCl}[1,4]$. Оба события, как демонстрируют представленные выше результаты, должны способствовать трансформации галлоцианина в его флуорогенную форму. Для того чтобы выяснить, какая из ферментных систем нейтрофилов в большей степени ответственна за превращение галлоцианина во флуорофор, мы активировали нейтрофилы добавлением $N$-формилметил-лейцил-фенилаланина (fMLP) или форбол12-миристат-13-ацетата (РМА) в присутствии галлоцианина и различных веществ, способных как
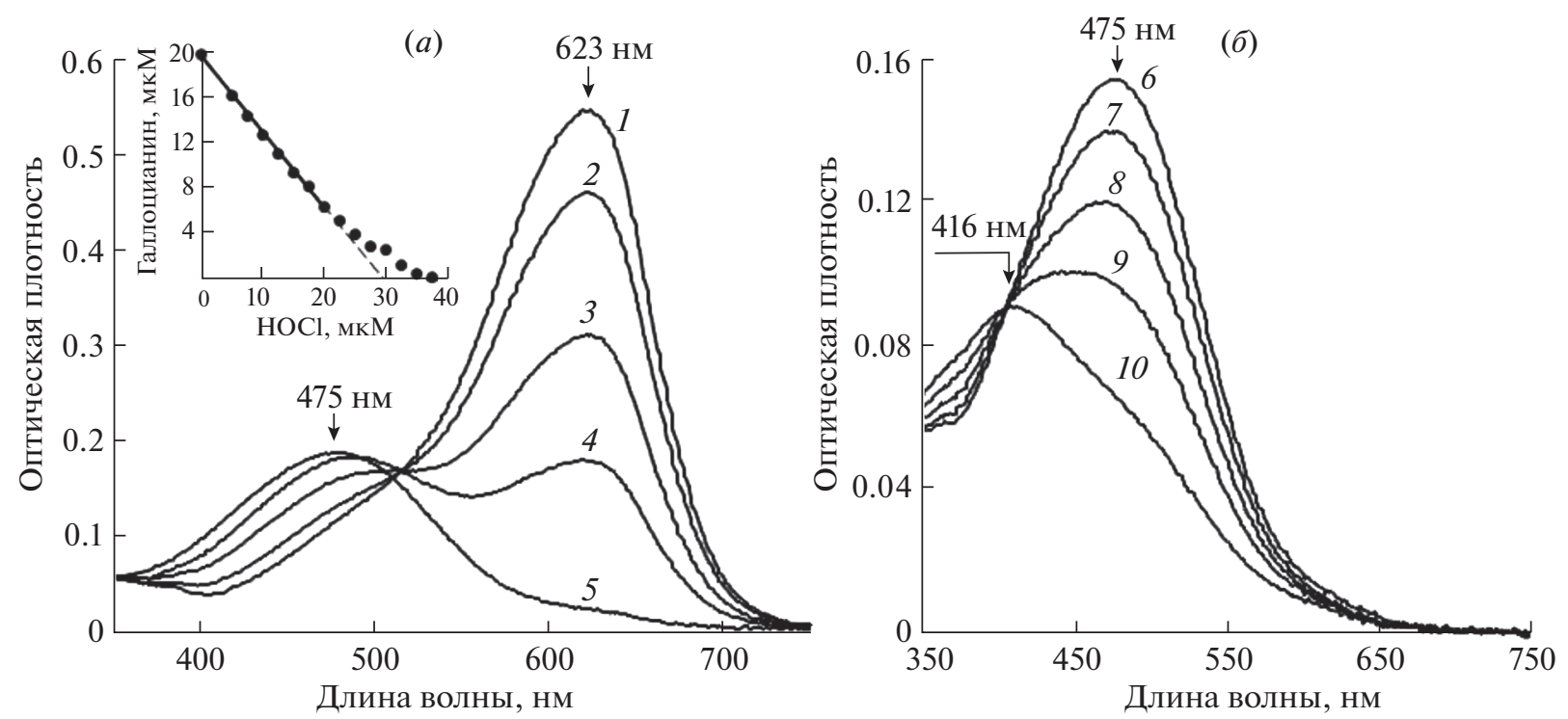

Рис. 6. Спектры поглощения галлоцианина до и после добавления к нему НОСl. Среда измерения - ФСБ-2, pН 7.4 (см. “Эксперим. часть”). Концентрация галлоцианина - 20 мкМ. Концентрация $\mathrm{HOCl}($ мкM) $(a): 1-0 ; 2-7.5 ; 3-$ $15.0 ; 4-22.5 ; 5-40.0 ;(6): 6-45.0 ; 7-52.5 ; 8-60.0 ; 9-67.5 ; 10-75.0$. На вставке приведена концентрационная зависимость убыли галлоцианина в растворе при добавлении к нему $\mathrm{HOCl}$, рассчитанная по убыли оптической плотности при 623 нм. 

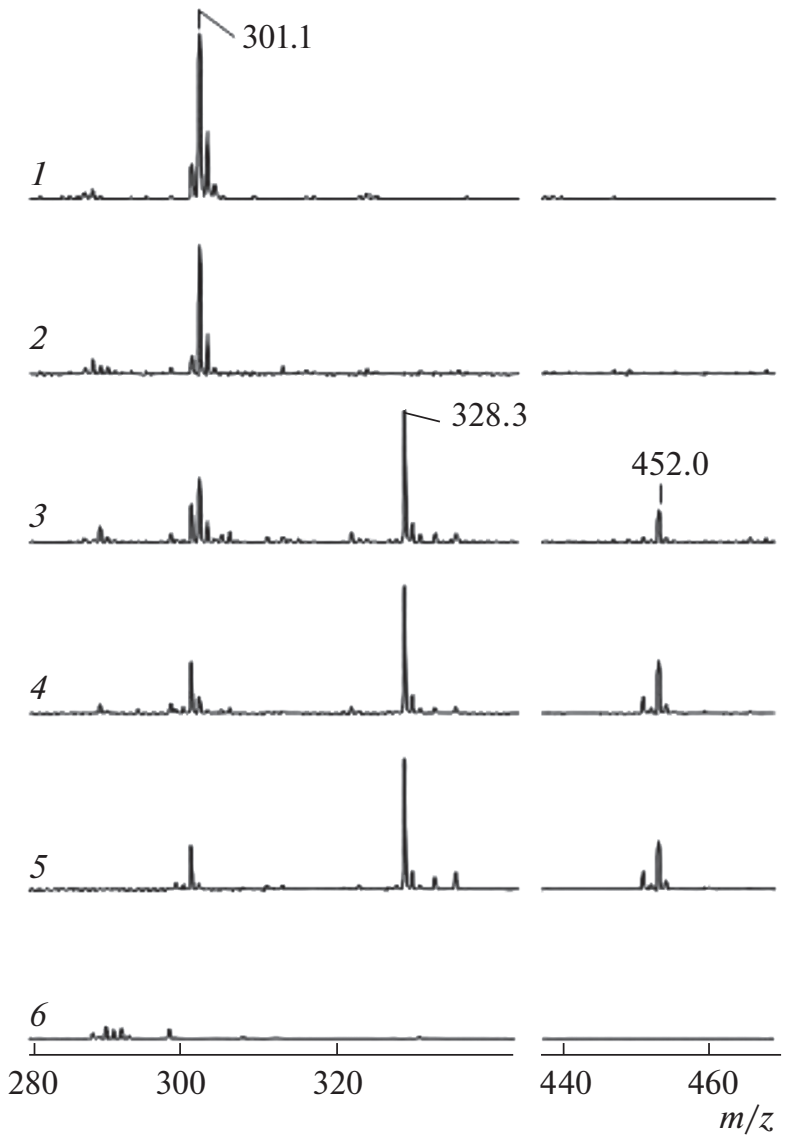

Рис. 7. Масс-спектры галлоцианина до и после добавления к нему $\mathrm{HOCl}$. Среда измерения - ФСБ-2, pH 7.4 (см. “Эксперим. часть”). Концентрация галлоцианина - 80 мкМ. Концентрация $\mathrm{HOCl}($ мМ): $1-0$; $2-0.4 ; 3-4.0 ; 4-8.0 ; 5-16.0 ; 6$ - масс-спектр матрицы (2,5-дигидроксибензойной кислоты) в отсутствие галлоцианина.

перехватывать и/или элиминировать АФК/АФГ, так и ингибировать их продукцию, регистрируя при этом изменение интенсивности флуоресценции. Результаты экспериментов приведены в табл. 1.

Из данных табл. 1 видно, что гидразид 4-аминобензойной кислоты (4-АВАН; специфический ингибитор каталитической активности МРО, а

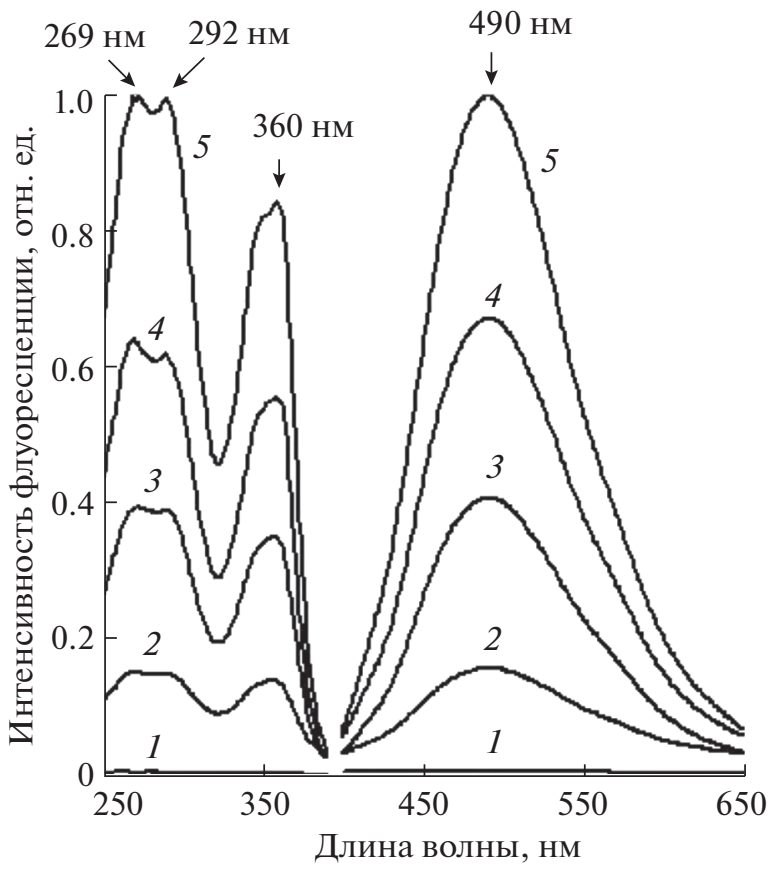

Рис. 8. Спектры возбуждения и испускания флуоресценции галлоцианина до и после добавления к нему $\mathrm{HOCl}$. Среда измерения - ФСБ-1, pH 7.4 (см. “Эксперим. часть”). Концентрация галлоцианина 5 мкМ. Концентрация НОСl (мкМ): $1-0 ; 2-2.5 ; 3-$ $5.0 ; 4-7.5 ; 5-10.0$. Возбуждение - при 360 нм, испускание - при 490 нм.

значит, и продукции $\mathrm{HOCl}$ [19]), таурин (перехватчик $\mathrm{HOCl}$ и маннитол (перехватчик гидроксильного радикала) не оказывали достоверного влияния на параметры окисления галлоцианина в присутствии активированных нейтрофилов. В то же время при добавлении к нейтрофилам SOD или церулоплазмина (CP) значения амплитуды интенсивности флуоресценции $\left(h_{7}\right)$ и скорости реакции $(v)$ были значительно ниже контроля (активация нейтрофилов fMLP или PMA без ингибиторов или перехватчиков АФК/АФГ) или не определялись вовсе в результате отсутствия прироста флуоресценции спустя 20 мин после активации нейтрофилов. Как известно, SOD элими-

Таблица 1. Влияние ингибиторов продукции АФК/АФГ и их перехватчиков на параметры, характеризующие химическое превращение галлоцианина в суспензии нейтрофилов, активированных fMLP или PMA

\begin{tabular}{l|l|c|c|c|c|c}
\hline Агонист & \multicolumn{1}{|c|}{ Параметр } & SOD, 1.6 мкM & CР, 1.1 мкM & 4-АВАН, 100 мкM & Таурин, 3.2 мМ & Маннитол, 10 мМ \\
\hline fMLP, & v, \% от контроля & $7 \pm 5^{*}$ & $5 \pm 4^{*}$ & $102 \pm 29$ & $98 \pm 27$ & $113 \pm 20$ \\
0.5 мкM & $h_{7}, \%$ от контроля & $14 \pm 4^{*}$ & $19 \pm 18^{*}$ & $129 \pm 30$ & $92 \pm 15$ & $107 \pm 35$ \\
РMA, & $v, \%$ от контроля & $0^{* *}$ & $2 \pm 3^{*}$ & $93 \pm 19$ & $105 \pm 20$ & $125 \pm 20$ \\
50 нM & $h_{7}, \%$ от контроля & $0^{* *}$ & $6 \pm 9^{*}$ & $127 \pm 23$ & $104 \pm 19$ & $110 \pm 15$ \\
\hline
\end{tabular}

$* p<0.05$.

** Полное отсутствие прироста флуоресценции спустя 20 мин после активации нейтрофилов. 
нирует ${ }^{\circ} \mathrm{O}_{2}^{-}$, катализируя его дисмутацию по реакции (2) до $\mathrm{H}_{2} \mathrm{O}_{2}$, который, как нам удалось установить, не реагирует с галлоцианином (см. выше). Обнаруженный эффект СР, по всей видимости, обусловлен SOD-активностью этого белка [20]. Полученные результаты позволяют предположить, что основной вклад в окисление галлоцианина в суспензии нейтрофилов происходит за счет его реакции с ${ }^{\circ} \mathrm{O}_{2}^{-}$.

Следует отметить, что в крови человека подавляющее количество МРО сосредоточено в нейтрофилах и лишь незначительная ее часть - в моноцитах $[1,4]$. Что касается NADPH-оксидазы, то различные ее изоформы присутствуют не только в нейтрофилах, но и практически во всех остальных типах клеток крови [2]: моноцитах [21], лимфоцитах [22], тромбоцитах [23], эритроцитах [24].

Таким образом, полученные результаты позволяют заключить, что галлоцианин может выполнять роль флуорогенного хемосенсора и использоваться для оценки NADPH-зависимой продукции супероксидного анион-радикала, по всей вероятности, не только нейтрофилами, но и другими клетками крови, а также для тестирования антиокислительных свойств препаратов, разрабатываемых с целью коррекции заболеваний, ассоциированных с окислительным стрессом.

\section{ЭКСПЕРИМЕНТАЛЬНАЯ ЧАСТЬ}

Реактивы. В работе использовали следующие реактивы: цитрат натрия, $N$-формил-метил-лейцил-фенилаланин (fMLP), форбол-12-миристат13-ацетат (РМА), гипохлорит натрия $(\mathrm{NaOCl})$, галлоцианин, диоксид калия $\left(\mathrm{KO}_{2}\right)$, ксантиноксидазу, ксантин, гидразид 4-аминобензойной кислоты (4-ABAH), супероксиддисмутазу (SOD), таурин, маннитол, 2,5-дигидроксибензойную кислоту фирмы Sigma (США); декстран T70 фирмы Roth (Германия); гистопак фирмы Nycomed (Hopвегия). Остальные реактивы были производства "Реахим” (Россия) и “Белмедпрепараты” (Беларусь). Церулоплазмин (СР) выделяли из крови здоровых доноров с помощью ионообменной и аффинной хроматографии [20].

Концентрацию гипохлорит-аниона $\left(\mathrm{OCl}^{-}\right)$определяли по его поглощению при 290 нм и рН 12, используя коэффициент молярной экстинкции $\varepsilon_{290}=350 \mathrm{M}^{-1} \mathrm{~cm}^{-1}$ [25]. Принимая во внимание тот факт, что $\mathrm{p} K_{\mathrm{a}} \mathrm{HOCl}$ составляет $\sim 7.5$ [25] и при физиологических значениях $\mathrm{pH}$ примерно половина кислоты находится в молекулярной форме, а остальная часть - в виде аниона, под $\mathrm{HOCl}$ мы подразумевали смесь $\mathrm{HOCl} / \mathrm{OCl}^{-}$, присутствующую в исследуемой среде.

В качестве буферного раствора использовали фосфатно-солевой буфер, содержавший $10 \mathrm{мM}$ $\mathrm{Na}_{2} \mathrm{HPO}_{4} / \mathrm{KH}_{2} \mathrm{PO}_{4}, 137 \mathrm{MM} \mathrm{NaCl}, 2.7 \mathrm{MM} \mathrm{KCl}$,
pH 7.4 (ФСБ-1) либо 10 мМ Na $2 \mathrm{HPO}_{4} / \mathrm{NaH}_{2} \mathrm{PO}_{4}$, pH 7.4 (ФСБ-2).

Спектры поглощения регистрировали на двухлучевых спектрофотометрах РВ 2201 (Solar, Беларусь) и Сary-50 (Varian, США).

Флуоресцентные измерения проводили на спектрофлуориметре СМ 2203 (Solar, Беларусь).

Выделение нейтрофилов осуществляли путем центрифугирования в градиенте плотности гистопака из крови здоровых доноров, как описано ранее [26]. Полученный осадок нейтрофилов отмывали в ФСБ- 1 , содержавшем 2 мг/мл $D$-глюкозы, при $4^{\circ} \mathrm{C}$ и сразу использовали в эксперименте.

Продукцию АФК и АФГ нейтрофилами оценивали флуоресцентным методом с использованием галлоцианина. $\mathrm{K}$ нейтрофилам $\left(10^{6}\right.$ кл./мл) в ФСБ- 1 , содержавшем $1 \mathrm{MM} \mathrm{CaCl}_{2}$ и $0.5 \mathrm{MM} \mathrm{MgCl}$, добавляли галлоцианин (5 мкM), fMLP (0.5 мкM) или РМА (50 нМ), ингибиторы продукции АФК/ АФГ или их перехватчики (SOD, 4-ABAH, CP, таурин, маннитол). Регистрацию осуществляли при $37^{\circ} \mathrm{C}$ и постоянном перемешивании образца. Продукцию ${ }^{\circ} \mathrm{O}_{2}^{-}$в системе ксантин/ксантиноксидаза регистрировали в ФСБ- 1 при $25^{\circ} \mathrm{C}$, концентрация ксантина -1 мМ, ксантиноксидазы -0.52 мкМ, галлоцианина -5 мкМ. Для регистрации флуоресценции эмпирически были подобраны значения длин волн возбуждения и испускания 360 и 490 нм соответственно. Для характеристики химического превращения красителя были выбраны следующие параметры (рис. 4): тангенс угла наклона начального линейного участка кинетической кривой изменения интенсивности флуоресценции $(v)$, характеризующий скорость реакции, и интенсивность флуоресценции образца по сравнению с фоновым уровнем через $7\left(h_{7}\right)$ или $20\left(h_{20}\right)$ мин после запуска активации нейтрофилов, отражающую количество накопившегося флуоресцирующего продукта реакции.

Масс-спектры регистрировали на масс-спектрометре Ultraflex II TOF/TOF (Bruker Daltonics, Германия), оснащенном УФ-лазером $(\mathrm{Nd})$, в режиме положительных ионов с использованием рефлектрона. Время задержки анализатора -200 нс. Напряжение на электроде ускорителя составляло $25.01 \mathrm{kB}$, накапливающем электроде - 21.71 кВ, фокусирующей линзе - 10.01 кВ. Параметры масс-спектрометра были оптимизированы для диапазона $m / z, 50-1000$. Сигнал накапливался как усредненный по 200 одиночным лазерным импульсам с постоянной мощностью лазерного излучения на уровне порогового значения для увеличения разрешения. В качестве матрицы использовали 2,5-дигидроксибензойную кислоту.

Статистическую и графическую обработку данных выполняли с использованием пакета программ OriginPro 2016. Данные представлены как 
среднее \pm стандартная ошибка среднего. Различия считали статистически достоверными при значении $p<0.05$, рассчитанном по критерию Стьюдента. Типичные кинетические кривые представляют собой инвариант 3-5 независимых экспериментов.

\section{ФОНДОВАЯ ПОДДЕРЖКА}

Работа выполнена при финансовой поддержке Российского фонда фундаментальных исследований (грант 20-515-00006) и Белорусского республиканского фонда фундаментальных исследований (грант Б20Р-215).

\section{СОБЛЮДЕНИЕ ЭТИЧЕСКИХ СТАНДАРТОВ}

Настоящая статья не содержит описания каких-либо исследований с использованием животных в качестве объектов.

Все процедуры, выполненные в исследовании с участием людей, соответствуют этическим стандартам институционального и/или национального комитета по исследовательской этике и Хельсинкской декларации 1964 года и ее последующим изменениям или сопоставимым нормам этики.

От каждого из включенных в исследование участников было получено информированное добровольное согласие.

\section{КОНФЛИКТ ИНТЕРЕСОВ}

Авторы заявляют об отсутствии конфликта интеpecoB.

\section{СПИСОК ЛИТЕРАТУРЫ}

1. Klebanoff S.J. // J. Leukoc. Biol. 2005. V. 77. P. 598625.

https://doi.org/10.1189/jlb.1204697

2. Меньщикова Е.Б., Зенков Н.К. // Усп. совр. биол. 2006. T. 126. C. 97-112.

3. Sies H. // Klin. Wochenschr. 1991. V. 69. P. 965-968. https://doi.org/10.1007/BF01645140

4. Панасенко О.М., Горудко И.В., Соколов А.В. // Усп. биол. химии. 2013. Т. 53. С. 195-244. [Panasenko O.M., Gorudko I.V., Sokolov A.V. // Biochemistry (Moscow). 2013. V. 78. P. 1466-1489.] https://doi.org/10.1134/S0006297913130075

5. Панасенко О.М., Сергиенко В.И. // Вестник Российской АМН. 2010. № 1. С. 27-39.

6. Huang J., Milton A., Arnold R.D., Huang H., Smith F., Panizzi J.R., Panizzi P. // J. Leukoc. Biol. 2016. V. 99. P. 541-548. https://doi.org/10.1189/jlb.3RU0615-256R

7. Tarpey M.M., Fridovich I. // Circ. Res. 2001. V. 89. P. 224-236. https://doi.org/10.1161/hh1501.094365

8. Kettle A.J., Albrett A.M., Chapman A.L., Dickerhof N., Forbes L.V., Khalilova I., Turner R. // Biochim. Bio- phys. Acta. 2014. V. 1840. P. 781-793. https://doi.org/10.1016/j.bbagen.2013.07.004

9. Setsukinai K., Urano Y., Kakinuma K., Majima H.J., Nagano T. // J. Biol. Chem. 2013. V. 278. P. 3170-3175. https://doi.org/10.1074/jbc.M209264200

10. Votyakova T.V., Reynolds I.J. // Arch. Biochem. Biophys. 2004. V. 431. P. 138-144. https://doi.org/10.1016/j.abb.2004.07.025

11. Grivennikova V.G., Kareyeva A.V., Vinogradov A.D. // Redox Biol. 2018. V. 17. P. 192-199. https://doi.org/10.1016/j.redox.2018.04.014

12. Sokolov A.V., Kostevich V.A., Kozlov S.O., Donskyi I.S., Vlasova I.I., Rudenko A.O., Zakharova E.T., Vasilyev V.B., Panasenko O.M. // Free Radic. Res. 2015. V. 49. P. 777-789. https://doi.org/10.3109/10715762.2015.1017478

13. Козлов С.О., Кудрявцев И.В., Грудинина Н.А., Костевич В.А., Панасенко О.М., Соколов А.В., Васильев В.Б. // Бюллетень ВСНЦ СО РАМН. 2016. T. 1. № 3 (109). Часть 2. С. 86-91.

14. Загородний В.В. // Архив патологии. 1982. Т. 44. C. 67-68.

15. Brown A., Scholtz C.L. // Stain Technol. 1979. V. 54. P. 89-92. https://doi.org/10.3109/10520297909112640

16. Borges F., Fernandes E., Roleira F. // Curr. Med. Chem. 2002. V. 9. P. 195-217. https://doi.org/10.2174/0929867023371229

17. Balavoine G.G., Geletii Y.V. // Nitric Oxide. 1999. V. 3. P. 40-54. https://doi.org/10.1006/niox.1999.0206

18. Kettisen K., Bulow L., Sakai H. // Bioconjug. Chem. 2015. V. 26. P. 746-754. https://doi.org/10.1021/acs.bioconjchem.5b00076

19. Malle E., Furtmüller P.G., Sattler W., Obinger C. // Br. J. Pharmacol. 2007. V. 152. P. 838-854. https://doi.org/10.1038/sj.bjp.0707358

20. Sokolov A.V., Kostevich V.A., Varfolomeeva E.Y., Grigorieva D.V., Gorudko I.V., Kozlov S.O., Kudryavtsev I.V., Mikhalchik E.V., Filatov M.V., Cherenkevich S.N., Panasenko O.M., Arnhold J., Vasilyev V.B. // Biochem. Cell Biol. 2018. V. 96. P. 457-467. https://doi.org/10.1139/bcb-2017-0277

21. Okura Y., Yamada M., Kuribayashi F., Kobayashi I., Ariga T. // J. Clin. Immunol. 2015. V. 35. P. 158-167. https://doi.org/10.1007/s10875-015-0138-4

22. Bánfi B., Molnár G., Maturana A., Steger K., Hegedûs B., Demaurex N., Krause K.H. // J. Biol. Chem. 2001. V. 276. P. 37594-37601. https://doi.org/10.1074/jbc.M103034200

23. Fuentes E., Gibbins J.M., Holbrook L.M., Palomo I. // Trends Cardiovasc. Med. 2018. V. 28. P. 429-434. https://doi.org/10.1016/j.tcm.2018.03.001

24. George A., Pushkaran S., Konstantinidis D.G., Koochaki S., Malik P., Mohandas N., Zheng Yi., Joiner C.H., Kalfa T.A. // Blood. 2013. V. 121. P. 2099-2107. https://doi.org/10.1182/blood-2012-07-441188

25. Morris J.C. // J. Phys. Chem. 1966. V. 70. P. 3798-3805.

26. Timoshenko A.V., Kayser K., Gabius H.J. // Lectin Methods and Protocols / Eds. Rhodes J.M., Milton J.D. Humana Press, 1998. P. 441-451. https://doi.org/10.1385/0-89603-396-1:441 


\title{
Gallocyanine as a Fluorogen for Identification of NADPH-Dependent Production of Superoxide by Blood Cells
}

\author{
O. M. Panasenko*,\#, V. E. Reut**, I. V. Borodina*, D. S. Matyushkina*, V. A. Ivanov*, \\ D. V. Grigorieva**, I. V. Gorudko**, A. V. Sokolov*, ***, and S. N. Cherenkevich** \\ "Phone: +7(499) 246-44-90; e-mail: o-panas@mail.ru \\ * Federal Research and Clinical Center of Physical-Chemical Medicine of Federal Medical Biological Agency, \\ ul. Malaya Pirogovskaya 1a, Moscow, 119435 Russia \\ **Belarusian State University, prosp. Nezavisimosti 4, Minsk, 220030 Belarus \\ *** Institute of Experimental Medicine, ul. Academica Pavlova 12, Saint Petersburg, 197376 Russia
}

In this work spectrophotometry, mass spectrometry and fluorescence spectroscopy methods were used to investigate interaction of the oxazine dye gallocyanine with reactive oxygen $\left({ }^{\circ} \mathrm{O}_{2}^{-}, \mathrm{H}_{2} \mathrm{O}_{2}\right)$ and halogen $(\mathrm{HOCl})$ species. It was shown that gallocyanine reacts with $\mathrm{HOCl}$ and ${ }^{\circ} \mathrm{O}_{2}^{-}$but not with $\mathrm{H}_{2} \mathrm{O}_{2}$ to form fluorescent products. Using inhibitory analysis it was found that both in xanthine/xanthine oxidase and in activated human blood neutrophil systems, reaction with ${ }^{\circ} \mathrm{O}_{2}^{-}$is responsible for gallocyanine conversation to fluorescent form. Results obtained in this study suggest that gallocyanine can act as a fluorogenic chemosensor for assessing neutrophil activation, NADPH-dependent production of superoxide anion radicals by these and other blood cells, as well as for testing antioxidant drugs, designed to intervene in disease associated with oxidative stress.

Keywords: gallocyanine, reactive oxygen species, reactive halogen species, oxidative stress, superoxide anion radical, hypochlorous acid, fluorescence 